\title{
Radiologically Isolated Syndrome: A Review for Neuroradiologists
}

\author{
(D) M. Hosseiny, (DS.D. Newsome, and (DD.M. Yousem
}

\begin{abstract}
SUMMARY: Radiologically isolated syndrome refers to an entity in which white matter lesions fulfilling the criteria for multiple sclerosis occur in individuals without a history of a clinical demyelinating attack or alternative etiology. Since its introduction in 2009, the diagnostic criteria of radiologically isolated syndrome and its clinical relevance have been widely debated by neurologists and radiologists. The aim of the present study was to review the following: 1) historical evolution of radiologically isolated syndrome criteria, 2) clinical and imaging findings in adults and children with radiologically isolated syndrome, 3) imaging features of patients with radiologically isolated syndrome at high risk for conversion to MS, and 4) challenges and controversies for work-up, management, and therapeutic interventions of patients with radiologically isolated syndrome.
\end{abstract}

ABBREVIATIONS: CIS = clinically isolated syndrome; DIS = dissemination in space; DIT = dissemination in time; MAGNIMS = Magnetic Resonance Imaging in MS; RIS = radiologically isolated syndrome; RRMS = relapsing-remitting multiple sclerosis; CADASIL = cerebral autosomal dominant arteriopathy with subcortical infarcts and leukoencephalopathy; ADEM = acute disseminated encephalomyelitis

$\mathbf{R}$ adiologically isolated syndrome (RIS) refers to an entity in which brain or spine MR imaging or both demonstrate incidental white matter lesions that are characteristic in morphology and location of a demyelinating disease, fulfilling the revised 2017 McDonald Criteria for dissemination in space (DIS) (On-line Table), ${ }^{1}$ but without a clinical history of demyelinating attacks or ongoing neurologic deterioration or other alternative causes of the white matter lesions such as those from vascular, infectious, toxic, and drug-related pathology. ${ }^{2}$ Some might argue that RIS is not truly a clinical diagnosis and instead is part of a continuum from health to disease that cannot currently be distinguished on the basis of imaging and clinical features.

The widespread use of brain MR imaging in multiple settings has led to frequent reporting of such incidental lesions on T2weighted and FLAIR pulse sequences. ${ }^{3}$ In most cases of RIS,

Received April 10, 2020; accepted after revision May 4.

From the Department of Radiological Sciences (M.H.), David Geffen School of Medicine at the University of California, Los Angeles, Los Angeles, California; Department of Neurology (S.D.N.), Johns Hopkins University School of Medicine, Baltimore, Maryland; and Russell H. Morgan Department of Radiology and Radiological Sciences (D.M.Y.), Johns Hopkins Medical Institution, Baltimore, Maryland.

Please address correspondence to David M. Yousem, MD, MBA, Johns Hopkins Medical Institution, 600 North Wolfe St, Phipps B112D, Baltimore, MD 21287; e-mail: dyousem1@jhu.edu; @dyousem1

- Indicates open access to non-subscribers at www.ajnr.org

Indicates article with supplemental on-line table.

http://dx.doi.org/10.3174/ajnr.A6649 patients are being evaluated for headache, trauma, or nonspecific dizziness, symptoms that are not characteristically attributed to MS, and they have not had prior clinical episodes of neurologic deficits.

While the prevalence of RIS remains unknown, incidentally found white matter lesions resembling demyelination occur in $0.1 \%-0.7 \%$ of the general population. ${ }^{4}$ The incidence of RIS has been estimated at 0.8 per 100,000 person-years in a Swedish cohort consisting of 1907 patients, compared with the 10.2 per 100,000 person-year incidence of MS. ${ }^{5}$ The prevalence of RIS is known to be increased in healthy relatives of patients with MS. Gabelic et $\mathrm{al}^{6}$ found that the prevalence of RIS was $2.9 \%$ in the healthy relatives of patients with MS in contrast to the prevalence of $2.4 \%$ in nonfamilial healthy controls. Liu et $\mathrm{al}^{7}$ assessed T2 hyperintensities in 326 consecutive patients $10-55$ years of age presenting with headache and found that the Barkhof and $2010 \mathrm{McDonald}$ criteria for DIS were met in $2.4 \%-7.1 \%$ and $24.4 \%-34.5 \%$, respectively. These reported figures, however, far exceed the prevalence of MS. Overall, on the basis of postmortem studies, the prevalence of RIS seems to fall within $0.06 \%-0.7 \%{ }^{8}$

Since RIS was first defined in $2009,{ }^{9}$ the implications of these imaging findings have been widely investigated. The conversion rate of RIS to MS and the debate over whether to start MS disease-modifying therapies (with their potentially serious side effects) in RIS are subjects of intense scrutiny, summarized herein. ${ }^{10}$ 


\begin{tabular}{|c|c|}
\hline Inclusion Criteria & Exclusion Criteria \\
\hline $\begin{array}{l}\text { CNS white matter lesions on MR imaging that are ovoid, well- } \\
\text { circumscribed, }>3 \mathrm{~mm} \text {, and homogeneously hyperintense on T2- }\end{array}$ & $\begin{array}{l}\text { CNS lesions in a vascular pattern } \\
\text { Historical accounts of remitting clinical symptoms consistent }\end{array}$ \\
\hline $\begin{array}{l}\text { CNS lesions fulfill } 3 \text { of } 4 \text { Barkof criteria } \\
\text { 1) One gadolinium-enhancing lesion or } 9 \text { T2-hyperintense lesions if no } \\
\text { gadolinium-enhancing lesions }\end{array}$ & $\begin{array}{l}\text { MR imaging anomalies can be explained by the direct } \\
\text { physiologic effects of substances (recreational drug abuse, } \\
\text { toxic exposure) or a medical condition }\end{array}$ \\
\hline 2) At least 1 infratentorial lesion & MR imaging phenotypes suggestive of leukoaraiosis (small- \\
\hline 3) At least 1 juxtacortical lesion, and & vessel ischemic disease) or extensive white matter \\
\hline 4) At least 3 periventricular lesions & pathology lacking involvement of the corpus callosum \\
\hline $\begin{array}{l}\text { MR imaging anomalies do not account for clinically apparent } \\
\text { impairment in social, occupational, or generalized areas of } \\
\text { functioning }\end{array}$ & $\begin{array}{l}\text { White matter lesions are better accounted for by another } \\
\text { medical condition }\end{array}$ \\
\hline
\end{tabular}

\section{History}

Okuda et $\mathrm{al}^{9}$ first described RIS as showing T2-hyperintence, ovoid, homogeneous, well-defined lesions on MR imaging that fulfilled at least 3 of 4 Barkhof criteria (Table 1) for DIS in individuals without a history of symptoms consistent with a central nervous system demyelinating disorder, toxic conditions, or other disease processes that might lead to such imaging findings. Development of clinically isolated syndrome (CIS) or clinically definite MS was noted in the longitudinal follow-up of 10 of 30 patients for which such data were available. The mean time to the first clinically defining neurologic event was 5.4 years. ${ }^{9}$

Nine articles on the topic were written in 2009 after the article by Okuda et al. ${ }^{9}$ Since then, the literature has expanded with 16 articles on the topic written in 2014 and 27 in 2019. However, there has not been a review of the imaging findings of RIS in a radiology-based scientific journal to date.

\section{Criteria Evolution}

The diagnosis of RIS has relied on the imaging criteria used to make the diagnosis of MS. The 2010 McDonald Criteria simplified the DIS criteria for the diagnosis of MS by focusing on the distribution of the demyelinating lesions (juxtacortical, periventricular, infratentorial, and spinal cord) rather than the total number of lesions. ${ }^{11}$ The 2010 and 2017 revised McDonald criteria did not address the RIS entity because of the paucity of longitudinal data surrounding RIS. However, in 2017, the Magnetic Resonance Imaging in MS (MAGNIMS) European group tried to better define the imaging criteria for RIS. The MAGNIMS consensus group did not propose a strict recommendation on diagnosing and treating RIS; however, they suggested that identical MR imaging criteria for DIS and dissemination in time (DIT) should be used for RIS and MS (Table 2). ${ }^{1}$
In other words, instead of using the Barkhof criteria as proposed in Okuda et $\mathrm{al}^{9}{ }^{9}$ the revised $2017 \mathrm{McDonald}$ and/or MAGNIMS criteria should be applied (On-line Table). On the basis of the new guidelines, DIS in RIS is based on the presence of T2/FLAIR hyperintense lesions in at least 2 of the following topographies: cortical or juxtacortical white matter, periventricular white matter, spinal cord, and the infratentorial (brain stem and/or cerebellum) compartment (Fig 1).

A detailed clinical history and a meticulous neurologic examination are essential to rule out any clinical evidence of MS before labeling the patient as fulfilling the definition of RIS. The criteria used for diagnosing clinically definite MS require the presence of clinical relapses (relapsing-onset MS) or ongoing neurologic deterioration from the start (progressive onset). ${ }^{2}$ MAGNIMS opined and the 2017 McDonald Criteria Panel agreed that if a clinical episode occurs in a subject positive for RIS-DIS/DIT then a diagnosis of MS can be made.

\section{Imaging Findings}

In the article of Okuda et $\mathrm{al}^{9}$ on RIS, 10 of 41 (24\%) patients with periventricular, juxtacortical, spinal, or infratentorial white matter lesions had $\geq 1$ enhancing plaque at the time of RIS presentation. Of these 41 patients, MR imaging progression (the presence of new T2 foci, new gadolinium enhancement, or enlargement of pre-existing lesions) on longitudinal MR imaging, fulfilling the DIT criteria, was identified in $59 \%$ of the cohort (24/41). In a subsequent multicenter cohort of 456 patients with RIS, the frequency of periventricular, juxtacortical, spinal cord, and infratentorial lesions was $98.7 \%$, $90.1 \%, 35.2 \%$, and $30.4 \%$, respectively. ${ }^{12}$ Gadolinium-enhancing lesions were found in $82.3 \%$ of this study cohort (Fig 2). ${ }^{12}$ In a study of 19 patients with RIS and 20 individuals with relapsing-remitting MS (RRMS), no significant difference was found between the

Table 2: Modified criteria for the diagnosis of RIS ${ }^{2}$

\begin{tabular}{ll}
\multicolumn{1}{c}{ Inclusion Criteria } & \multicolumn{1}{c}{ Exclusion Criteria } \\
\hline$\geq 1$ T2-hyperintense lesions on T2-weighted scans involving & $\begin{array}{c}\text { Neurologic dysfunction suggestive of MS based on historical } \\
\text { at least } 2 \text { of the following } 4 \text { locations: } \\
\text { symptoms and/or objective signs }\end{array}$ \\
$\begin{array}{l}\text { 1. Periventricular white matter } \\
\text { 2. Cortical/juxtacortical }\end{array}$ & $\begin{array}{l}\text { especially considering age, vascular, toxins, or drug-related } \\
\text { abnormalities }\end{array}$ \\
$\begin{array}{l}\text { 3. Spinal cord } \\
\text { 4. Infratentorial }\end{array}$ & \\
\hline
\end{tabular}



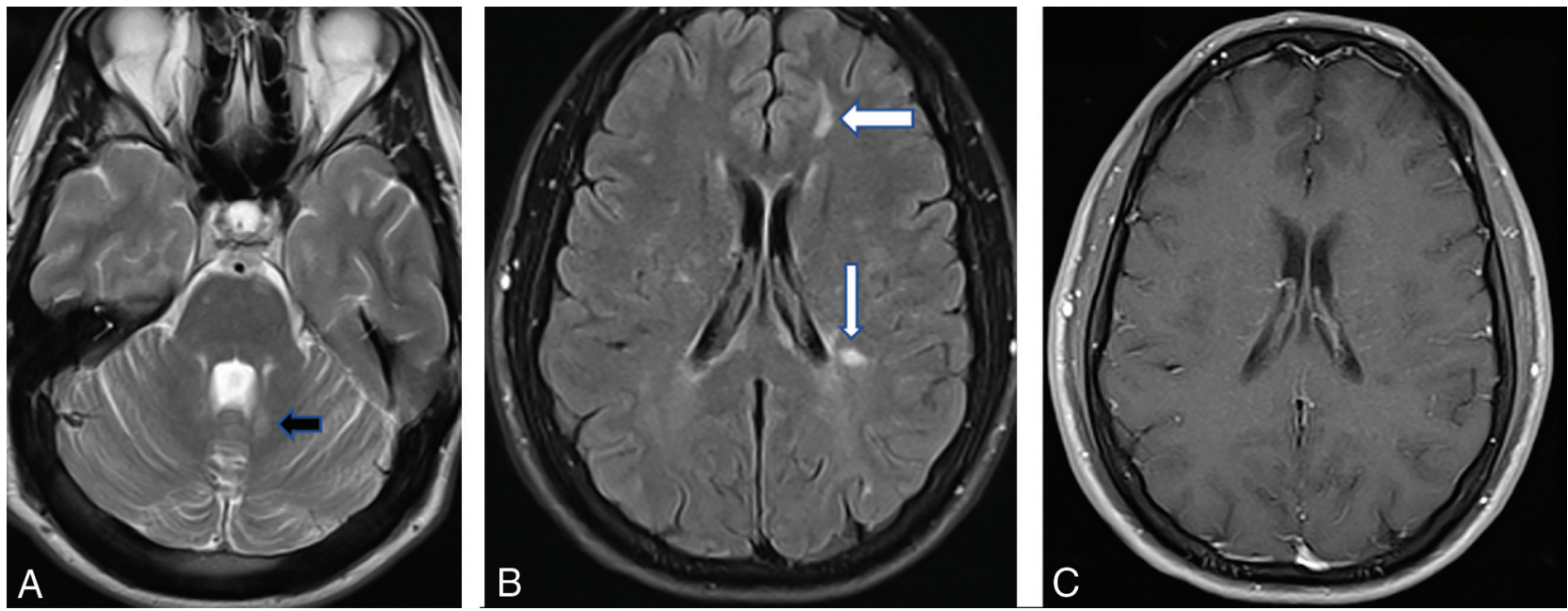

FIG 1. A, Axial T2-weighted image in a 21-year-old patient presenting to the emergency department with the worst headache of her life shows left periventricular posterior fossa lesions (arrow). B. The FLAIR scan demonstrates periventricular (Dawson fingers-like) and juxtacortical lesions (arrows). C, None of the lesions show gadolinium enhancement.

groups in T1-weighted and T2-weighted lesion volume or frequency and distribution of lesions. ${ }^{13}$ In addition to white matter lesions, cortical lesions have been described in $40 \%$ of patients with RIS in a study by Giorgio et al. ${ }^{14}$ The authors found that these cortical lesions involved the frontotemporal lobes most commonly and were more frequent in patients with RIS with the following: 1) oligoclonal bands in the CSF, 2) DIT on follow-up, and 3) coexistent cervical cord lesions. The unanswered question remains as to whether patients with RIS with cortical lesions have a higher MS conversion rate.

The perivenular distribution of the lesions is a key feature in distinguishing RIS from other mimickers (eg, migraines, strokes, synovitis-acne-pustulosis-hyperostosis-osteitis syndrome). A high percentage of RIS lesions show the central vein sign, specifically when higher magnetic fields and susceptibility-weighted sequences are used. ${ }^{15,16}$ The paramagnetic rim sign refers to the signal drop (ie, susceptibility artifact) at the edge of the white matter lesions in chronic demyelination. A study of 15
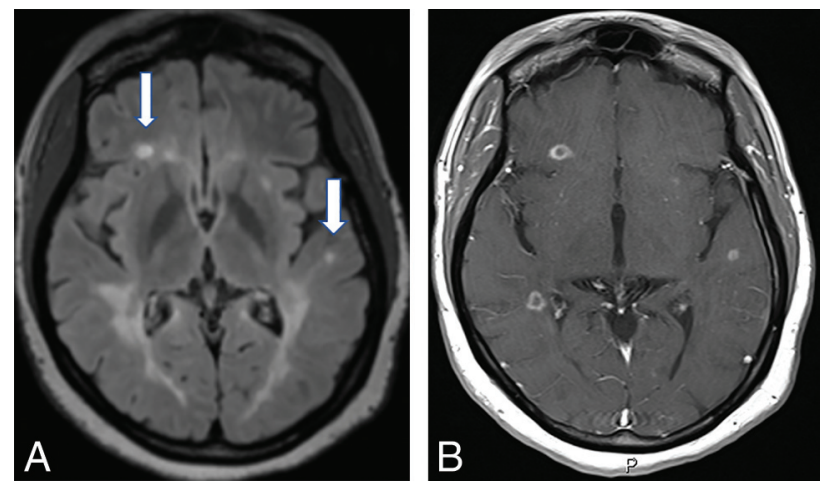

FIG 2. A, A 32-year-old woman being evaluated for benign positional vertigo. The FLAIR scans have severe confluent periventricular disease and a few juxtacortical foci (arrows) of high signal. B, On postgadolinium scanning, numerous ring-enhancing demyelinating lesions are present, both periventricular-periatrial on the right and juxtacortical bilaterally. individuals with RIS reported the central vein sign and paramagnetic rim sign in $93 \%$ and $73 \%$ of the study population, respectively. ${ }^{17}$

\section{Advanced Imaging}

On 3D quantitative volumetric studies, normalized whole-brain volume, normalized cerebral cortical volume, ${ }^{18}$ and normalized cerebellar white matter volume ${ }^{19}$ have been found to be significantly lower in patients with RIS compared with healthy individuals. In addition, on MR spectroscopy studies, decreased $N$-acetyl-aspartate/ creatine levels in lesional regions, normal-appearing white matter, and cortical gray matter have been found in patients with RIS compared with healthy controls, suggestive of early neuronal damage. ${ }^{20}$

Studies using DTI have described microstructural changes in the brain MR imaging of individuals with RIS, which are confined to the lesional area; this finding is in contrast to the altered white matter integrity in both lesions and normal-appearing white matter in RRMS. De Stefano et al ${ }^{13}$ examined brain MRIs of 19 individuals with RIS compared with 20 with RRMS and 20 healthy controls. They found lesional magnetization transfer to be significantly lower in those with RIS than in healthy controls, but significantly higher than in those with RRMS. Normal-appearing white matter magnetization transfer values were similar in patients with RIS and healthy controls but significantly higher than normalappearing white matter in patients with RRMS.

Giogrio et $\mathrm{al}^{21}$ identified lower fractional anisotropy values in white matter tracts with lesions in patients with RIS compared with healthy controls. In addition, the study compared the functional connectivity in individuals with RRMS and RIS versus healthy controls. There was no difference in resting-state network connectivity among those with RIS, RRMS, and controls; however, patients with RIS had significantly lower functional connectivity in sensorimotor and working memory subnetworks than patients with RRMS.

Similar changes were reported in advanced MR imaging of the spinal cord in RIS. In a study ${ }^{22}$ of $3 \mathrm{~T}$ spinal cord MR imaging in 24 individuals with RIS and 14 healthy controls, the spinal 
cord magnetization transfer ratios were lower in patients with RIS. By contrast, there were no significant differences in the DTI metrics (fractional anisotropy and mean, perpendicular, and parallel diffusivity) between individuals with RIS and healthy controls.

\section{Evolution to MS}

A number of clinical and paraclinical features have been studied in RIS to help identify whether markers exist that portend early clinical conversion to MS. These predictors may help identify patients with high-risk RIS who might benefit from early treatment with MS disease-modifying therapies, though treatment is controversial at this juncture in time.

In a multicenter study of 451 individuals with RIS, approximately two-thirds of individuals developed new lesions on longitudinal MR imaging, while one-third of them developed CIS within 5 years of the index MR imaging. ${ }^{12}$ Since this publication in 2014, it has been accepted that RIS with DIS and DIT plus CIS implies a diagnosis of $\mathrm{MS}^{2}$ Approximately $10 \%$ of the entire cohort eventually developed primary-progressive MS.

Patients with spinal cord lesions appear to be at particular risk of conversion, with $56 \%$ converting to $\mathrm{MS}^{23}$ In 1 study of patients with RIS, $84 \%$ of individuals who had cervical cord lesions converted to MS, while only $7 \%$ of those without cervical cord lesions converted. ${ }^{24}$ Similarly, thoracic cord lesions, though occurring more rarely, place patients with RIS at higher risk of conversion to MS (hazard ratio, 2.23 versus 2.02 for cervical cord lesions). ${ }^{4}$

In contrast to spinal lesions, periventricular and juxtacortical lesions were not found to be predictive of clinical conversion. ${ }^{12,25}$ Additionally, the number of lesions and their location in the brain are not a strong predictor of clinical conversion. ${ }^{26}$ A few studies have found the presence of infratentorial lesions to be predictive of clinical conversion, ${ }^{24,27}$ while others have not. $^{12,25,28}$

Lebrun et $\mathrm{al}^{28}$ suggested that the criteria for high-risk RIS should include younger age, the presence of gadolinium-enhancing lesions, and abnormal visual-evoked potentials. According to the multinational study mentioned above ${ }^{12}$ that included 451 individuals with RIS (78.5\% females; mean age, 37.2 years), younger age (hazard ratio, 0.98; 95\% CI, 0.96-0.99), male sex (hazard ratio, 1.93; 95\% CI, 1.24-2.99), and the presence of lesions within the cervical or thoracic spinal cord (hazard ratio, 3.08; 95\% CI, 2.06-4.62) were identified in the multivariate analysis as the most significant predictors for the development of MS. The presence of contrast enhancement on baseline MR imaging, the location of the lesions in the brain, a family history of MS, and the CSF profile were not strong predictors of clinical conversion in this model. Older men with spinal cord lesions and RIS had a higher rate of conversion to primary-progressive MS. ${ }^{29}$

CSF biomarkers have also been studied in patients with RIS. Oligoclonal bands have been the most important CSF biomarker to predict clinical conversion to MS. ${ }^{26}$ In the $2017 \mathrm{McD}$ onald MS criteria, oligoclonal bands can replace DIT. ${ }^{1}$ Smaller cohorts have shown a higher risk if patients have elevated interleukin $8,{ }^{30}$ neurofilament light chain, ${ }^{31}$ and immunoglobulin $\mathrm{G}$ indexes ${ }^{23}$ in the spinal fluid.
Lebrun et $\mathrm{al}^{32}$ also found a higher rate of clinical conversion to MS in pregnant patients with a significantly shorter mean conversion time.

Overall, the presence of spinal cord lesions, oligoclonal bands in CSF, and younger age is the most important predictor for conversion. Whether the presence of contrast-enhancing lesions can be a predictor of clinical conversion is controversial.

\section{Relationship to Clinically Isolated Syndrome}

Patients are considered to have CIS when they present with their first clinical symptom suggestive of CNS demyelination and do not fulfill the McDonald criteria for clinically definite MS. The neurologic event might involve the optic nerve, spinal cord, brain stem, cerebellum, or cerebral hemispheres. The clinical event needs to persist in a constant fashion for at least 24 hours and occur in the absence of fever or infection to be called a demyelinating attack. ${ }^{1}$ In a study of 156 individuals with CIS with a median follow-up of 7 years, $42 \%$ converted to clinically definite MS. ${ }^{33}$ The rate of conversion of CIS to MS appears to be higher than that in individuals with RIS. MR imaging is the most helpful tool to predict conversion to MS in patients with CIS. MR imaging abnormalities suggestive of demyelinating disease are seen in $50 \%-70 \%$ of individuals with CIS. ${ }^{34}$ The risk of conversion to clinically definite MS is approximately $60 \%-82 \%$ in those with abnormal MR imaging findings, in contrast to $8 \%-$ $25 \%$ in those with a normal MR imaging findings. ${ }^{35}$ In individuals with RIS who develop CIS, the presence of DIT (eg, the presence of both gadolinium-enhancing and nonenhancing lesions) on MR imaging will fulfill the criteria for a diagnosis of MS. Several MR imaging features have been associated with a higher risk of conversion of CIS to MS, including the involvement of white matter tracts attributed to motor function, the involvement of tracts near the corpus callosum, ${ }^{36}$ the presence of spinal cord lesions, ${ }^{37}$ the development of new brain lesions, and lateral ventricle enlargement. ${ }^{38}$

\section{Differential Diagnosis}

As stated in the original article of Okuda et al, ${ }^{9}$ the label of RIS can be applied only after excluding other causes of white matter lesions. Okuda et al added, as part of these criteria (see Table 1), "The MR imaging anomalies are not due to the direct physiologic effects of substances (recreational drug abuse, toxic exposure) or a medical condition" and "Exclusion of individuals with MR imaging phenotypes suggestive of leukoaraiosis or extensive white matter pathology lacking involvement of the corpus callosum." Similarly, the MAGNIMS 2018 statement lists as exclusion criteria "MR imaging abnormalities explained by any other disease process, with particular attention to aging or vascularrelated abnormalities, and those due to exposure to toxins or drugs." ${ }^{2}$ These statements are included because an age limit has not been defined for RIS. Therefore, an elderly patient with small-vessel ischemic disease with lesions in the posterior fossa and periventricular region who develops a new ischemic focus may fulfill the McDonald 2017 and the RIS imaging criteria of Okuda et al.

When one considers the causes of white matter lesions that may mimic the RIS pattern, the list spans several entities 


\begin{tabular}{|c|c|c|c|}
\hline Entity & Distinguishing Clinical Features & Distinguishing Imaging Features & Important Keys to Diagnosis \\
\hline Toxins/drug-related & $\begin{array}{l}\text { Altered mental status changes } \\
\text { during intoxication, history of } \\
\text { substance abuse }\end{array}$ & $\begin{array}{l}\text { Deep gray matter frequently } \\
\text { involved, symmetric lesions }\end{array}$ & $\begin{array}{l}\text { Urine and serum toxicology } \\
\text { tests }\end{array}$ \\
\hline Age-related leukoaraiosis & $\begin{array}{l}\text { Older individual, cardiovascular } \\
\text { risk factors }\end{array}$ & $\begin{array}{l}\text { Small ( }<3 \mathrm{~mm} \text { ), nonenhancing } \\
\text { lesions in periventricular and deep } \\
\text { white matter, coexistent } \\
\text { striatocapsular lacunar disease, } \\
\text { absence of callososeptal lesions/ } \\
\text { Dawson fingers-type lesions }\end{array}$ & $\begin{array}{l}\text { Lacunar disease and atypical } \\
\text { white matter lesions for } \\
\text { RIS in an older individual }\end{array}$ \\
\hline Migraines & Headache or aura predominates & $\begin{array}{l}\text { Predominantly subcortical white } \\
\text { matter lesions that are small }(<3 \\
\mathrm{mm}) \text { and do not enhance, few } \\
\text { periventricular lesions }\end{array}$ & $\begin{array}{l}\text { Headache history and lack } \\
\text { of typical imaging features } \\
\text { consistent with RIS }\end{array}$ \\
\hline Vasculitis & $\begin{array}{l}\text { Episodic neurologic symptoms } \\
\text { with superimposed strokes }\end{array}$ & $\begin{array}{l}\text { Gray and white matter lesions } \\
\text { coexist, may have enhancing } \\
\text { vessel wall and/or leptomeningeal } \\
\text { enhancement, MRA with stenoses }\end{array}$ & $\begin{array}{l}\text { Systemic symptoms present, } \\
\text { elevated erythrocyte } \\
\text { sedimentation rate and/or } \\
\text { C-reactive protein level, } \\
\text { extra-/intracranial vessels } \\
\text { abnormal, brain biopsy }\end{array}$ \\
\hline CADASIL & $\begin{array}{l}\text { Strokelike episodes, family } \\
\text { history of similar clinical } \\
\text { syndrome }\end{array}$ & $\begin{array}{l}\text { White matter disease favoring } \\
\text { anterior temporal tip subcortical } \\
\text { regions, external capsule, } \\
\text { presence of lacunar infarcts }\end{array}$ & Genetic testing diagnostic \\
\hline Collagen vascular diseases & $\begin{array}{l}\text { Clinical history of arthritis, long- } \\
\text { standing chronic disease, } \\
\text { episodic }\end{array}$ & $\begin{array}{l}\text { Gray and white matter lesions } \pm \\
\text { vasculitis, occasional encephalitis }\end{array}$ & $\begin{array}{l}\text { Clinical symptoms of a } \\
\text { systemic disorder and } \\
\text { presence of serologic } \\
\text { autoantibodies/ } \\
\text { inflammatory markers }\end{array}$ \\
\hline ADEM & $\begin{array}{l}\text { Encephalitis, seizures, children } \\
>\text { adults, history of viral/ } \\
\text { vaccine prodrome }\end{array}$ & $\begin{array}{l}\text { Gray matter disease predominates, } \\
\text { more diffuse enhancement, may } \\
\text { have positive findings on DWI }\end{array}$ & $\begin{array}{l}\text { History of prodromal virus } \\
\text { infection or vaccination, } \\
\text { encephalopathic }\end{array}$ \\
\hline Posttraumatic & $\begin{array}{l}\text { History of } \geq 1 \text { traumatic, sports- } \\
\text { related event }\end{array}$ & $\begin{array}{l}\text { Favors gray-white matter junction, } \\
\text { hemorrhagic products present, } \\
\text { classic tears in splenium-brain } \\
\text { stem deep gray matter }\end{array}$ & $\begin{array}{l}\text { Hemorrhage and } \\
\text { stereotypical locations of } \\
\text { disease at shearing sites }\end{array}$ \\
\hline
\end{tabular}

Note:-ADEM indicates acute disseminated encephalomyelitis.

including vascular (migraine changes, vasculitis, CADASIL, neonatal hypoxic-ischemic injuries, anoxic episodes, and small-vessel ischemic disease), inflammatory/infectious entities (sarcoidosis, lupus, acute disseminated encephalomyelitis, progressive multifocal leukoencephalopathy, synovitis-acne-pustulosis-hyperostosis-osteitis syndrome), posttraumatic changes (remote clinical and subclinical trauma, sports-related, ie, boxers), drug-related (splenial demyelination in seizure medications versus causes of posterior reversible encephalopathy syndrome), and idiopathic (Table 3). ${ }^{39}$ Two series ${ }^{40,41}$ of "misdiagnosed MS" reported the most common final diagnoses to be migraine, fibromyalgia, psychiatric/psychogenic disease, nonspecific white matter abnormalities, small-vessel ischemic disease, and neuromyelitis optica spectrum disorders. As opposed to these entities described above, which have overt signs and symptoms, patients with RIS are, by definition, asymptomatic.

Despite this very broad differential diagnosis, subspecialtytrained neuroradiologists have been shown to be very accurate in recognizing the pattern of white matter lesions suggestive of MS and therefore RIS. In a study performed at a large academic center, ${ }^{42}$ the order in which MS was suggested in a differential diagnosis of the neuroradiologist's report determined the likelihood of a final diagnosis in patients who did not previously have a diagnosis of MS. When MS was listed as the only diagnosis, the neuroradiologists were correct in the final diagnosis in $22 / 24$ cases $(92.3 \%)$. When "demyelinating disorder" only was listed, they were correct in 43/51 cases (84.3\%), and when MS was listed as the first potential diagnosis in a list of differentials, the final diagnosis was proved to be MS in 38\% (3/8) of cases. The final diagnoses in those patients inaccurately reported as "likely MS" included migraines $(n=9)$, peripheral neuropathy $(n=4)$, postconcussive lesions $(n=3)$, substance abuse $(n=2)$, cerebrovascular disease $(n=$ $2)$, and no diagnosis $(n=5){ }^{42}$

The imaging findings that are more suggestive of RIS than other entities include the central vein sign of demyelination around a vein and involvement of the corpus callosum (corpus callosum-septum pellucidum interface). The original RIS diagnostic criteria of Okuda et $\mathrm{al}^{9}$ excluded patients if they were "lacking involvement of the corpus callosum." Moreover, spinal involvement also helps to practically exclude diagnoses like migraines, posterior reversible encephalopathy syndrome, progressive multifocal leukoencephalopathy, and so forth. A good review of the accuracy of MR imaging for MS alone and in combination with clinical findings, serologic tests, and CSF markers can be found in the study by Schaffler et al. ${ }^{43}$ 


\section{Clinical Approach to RIS}

Despite RIS being described more than a decade ago, there are no specific, universally adopted guidelines for the monitoring and treatment of this evolving entity. This issue is mostly secondary to a paucity of available longitudinal studies and lack of expert consensus $^{1}$ on how one should approach such patients. Hence, clinicians are left with relying on short studies, review articles, and their anecdotal experiences.

An initial pragmatic approach that many clinicians take after an individual fulfills the criteria for RIS is similar to how clinicians evaluate and monitor patients with suspected CIS and MS. First, a detailed history and physical examination by an experienced neurology clinician are recommended to ensure that a patient truly has RIS, especially because treatment is recommended for most patients with CIS and MS. The emphasis, therefore, is to discover prior or current neurologic signs and symptoms that might fulfill the CIS or MS criteria. At this juncture, most clinicians ${ }^{44-46}$ are hesitant to start patients with RIS on prophylactic disease-modifying therapies because a substantial number of patients with RIS will not develop MS and there are potential serious risks associated with MS therapies.

Obtaining paraclinical testing beyond an MR imaging is also extremely important because this can help stratify patients with RIS into low-risk (eg, no spine lesions, normal lumbar puncture) or high-risk (eg, spine lesions, presence of CSF-restricted oligoclonal bands) ${ }^{12,47}$ for conversion to MS. Hence, most neurology clinicians will recommend a lumbar puncture to assess markers of autoimmunity and inflammation, including CSF pleocytosis, an elevated immunoglobulin G index, and/or CSFrestricted oligoclonal bands. In addition, just like with MS, serologic testing is necessary for ruling out mimickers of demyelinating disorders (systemic/rheumatic disorders, nutritional deficiencies, infectious diseases, and so forth) and for identifying conditions that have a stronger propensity to cause disabling neurologic attacks (eg, seropositive neuromyelitis optica spectrum disorders, anti-myelin oligodendrocyte glycoproteinassociated disorders, and so forth).

Other tests that are commonly performed that may be associated with the prognosis of patients with RIS include visualevoked potential testing and optical coherence tomography. ${ }^{28,48,49}$ Electromyography, nerve conduction studies, and other ancillary studies are typically not performed unless there are "red flags" in the history and/or examination suggesting an alternative diagnosis (eg, peripheral neuropathy).

Most clinicians will also obtain a total serum 25-hydroxyvitamin $\mathrm{D}$ level on their patients because chronic vitamin $\mathrm{D}$ deficiency is associated with a risk of developing MS. ${ }^{50}$ If a patient with RIS has low vitamin $\mathrm{D}$, vitamin $\mathrm{D}$ supplementation is recommended.

After the initial assessment and work-up for RIS is completed, clinicians are then challenged by how patients with RIS should be monitored across time. Currently, there is a paucity of data that help guide clinicians on when surveillance imaging should be performed in RIS, especially as it relates to assessing evidence of DIT. ${ }^{2,51}$ The MAGNIMS group and the Consortium of Multiple Sclerosis Centers MR Imaging Task Force have published expert consensus guidelines that can be followed. ${ }^{2,51}$ Future and ongoing prospective longitudinal studies will help refine these guidelines along with the advent of newer imaging techniques (central vein sign, paramagnetic rim sign) and other biomarkers (eg, neurofilament light chain).

At this time, the treatment approach for patients with RIS is controversial. As previously highlighted, a substantial number of patients with RIS will not develop CIS or MS, especially those who are considered to have low-risk RIS. A recent comprehensive review article ${ }^{52}$ on RIS discussed the importance of clinical trials in RIS because data are lacking establishing the benefit of starting treatment in RIS. Hence, treatment is not recommended for most upfront, though if new inflammatory activity (ie, gadoliniumenhancing lesions) is seen on follow-up MR imaging, many neurologists would strongly consider starting therapy.

In 1 retrospective study in which a small cohort of patients with RIS received MS disease-modifying therapies, the 5-year risk of developing an MS-defining clinical event was 45\% (33/73 patients) in those receiving disease-modifying therapies versus $31 \%(117 / 378)$ in those who did not receive disease-modifying therapies. ${ }^{12}$ There are several RIS randomized clinical trials ongoing that are evaluating whether starting dimethyl fumarate or teriflunomide will prevent or delay conversion to clinically definite MS versus a placebo.

\section{RIS in Pediatrics}

There are limited data on the prevalence and clinical significance of RIS in children. In a review of brain MRIs in 3966 pediatric patients, ${ }^{53}$ only 1 patient $(0.03 \%)$ was identified as fulfilling the RIS criteria. In a longitudinal multicenter study ${ }^{54}$ of 38 pediatric patients with a median age of 15 years who were diagnosed with RIS based on the McDonald 2010 DIS criteria, 42\% experienced a first clinical neurologic attack with a median interval of 2 years. In addition, radiologic progression was reported in $61 \%$ of the study cohort. These reported numbers are very similar to those of RIS in adult patients; however, the study found that clinical conversion to MS occurs after a shorter interval in pediatric patients compared with adults. Most important, the authors also reported that the presence of $\geq 2$ CSF-related oligoclonal bands or spinal cord lesions was a significant predictor of clinical conversion. ${ }^{55}$ The conventional MR imaging findings in children are not different from those seen in adult patients with RIS. Because there are sparse data available on RIS in children, there is not sufficient evidence to conclude that these patients could potentially benefit from early disease-modifying treatment. ${ }^{56}$

\section{CONCLUSIONS}

There are patients without a defined neurologic event who have MR imaging findings that fulfill the imaging criteria for MS. After an extensive work-up to exclude other neurologic, systemic, or iatrogenic etiologies, these patients are labeled as fulfilling the criteria for RIS. At baseline and in follow-up, the presence of imaging factors (spinal lesions, enhancing lesions, corpus callosum lesions), demographic characteristics (men, pregnant women, younger age, relative of a patient with MS), and/or CSF markers (oligoclonal bands) incurs a higher risk of subsequent conversion to MS. Radiologists who identify patients with classic MS-like lesions in the appropriate clinical and patient group settings should suggest 
the RIS entity. The surveillance of patients with RIS, the agent and extent of treatment, and long-term outcomes are subjects of ongoing debate and clinical trials. More studies are also needed with advanced MR imaging techniques to investigate whether novel technologies being developed will help identify which patients with RIS are at greatest risk for conversion to clinically definite MS.

Disclosures: Scott D. Newsome-UNRELATED: Consultancy: Biogen, Genentech, Celgene, EMD Serono, Comments: attended scientific advisory board meetings; Grants/Grants Pending: Biogen, Novartis, Genentech, National Multiple Sclerosis Society, Department of Defense, and Patient-Centered Outcomes Research Institute*; Other: Gerson Lehrman Group, Biolncept, and MedDay Pharmaceuticals, Comments: advisor for Gerson Lehrman Group and Biolncept and a clinical adjudication committee member for a MedDay Pharmaceuticals clinical trial. David M. Yousem-UNRELATED: Board Membership: mrionline.com, Comments: unpaid board member; Expert Testimony: medicolegal reviews; Payment for Lectures Including Service on Speakers Bureaus: mrionline.com, American College of Radiology speaker; Royalties: Elsevier for 5 books, informational analytics for peer review program; Payment for Development of Educational Presentations: mrionline.com. *Money paid to the institution.

\section{REFERENCES}

1. Thompson AJ, Banwell BL, Barkhof F, et al. Diagnosis of multiple sclerosis: 2017 revisions of the McDonald criteria. Lancet Neurol 2018;17:162-73 CrossRef Medline

2. De Stefano N, Giorgio A, Tintoré M, et al; MAGNIMS study group. Radiologically isolated syndrome or subclinical multiple sclerosis: MAGNIMS consensus recommendations. Mult Scler 2018;24:21421 CrossRef Medline

3. Morris Z, Whiteley WN, Longstreth WT Jr, et al. Incidental findings on brain magnetic resonance imaging: systematic review and meta-analysis. BMJ 2009;339:b3016 CrossRef Medline

4. Yamout B, Al Khawajah M. Radiologically isolated syndrome and multiple sclerosis. Mult Scler Relat Disord 2017;17:234-37 CrossRef Medline

5. Forslin Y, Granberg T, Jumah AA, et al. Incidence of radiologically isolated syndrome: a population-based study. AJNR Am J Neuroradiol 2016;37:1017-22 CrossRef Medline

6. Gabelic T, Ramasamy DP, Weinstock-Guttman B, et al. Prevalence of radiologically isolated syndrome and white matter signal abnormalities in healthy relatives of patients with multiple sclerosis. AJNR Am J Neuroradiol 2014;35:106-12 CrossRef Medline

7. Liu S, Kullnat J, Bourdette D, et al. Prevalence of brain magnetic resonance imaging meeting Barkhof and McDonald criteria for dissemination in space among headache patients. Mult Scler 2013;19:110105 CrossRef Medline

8. Granberg T, Martola J, Kristoffersen-Wiberg M, et al. Radiologically isolated syndrome-incidental magnetic resonance imaging findings suggestive of multiple sclerosis, a systematic review. Mult Scler 2013;19:271-80 CrossRef Medline

9. Okuda DT, Mowry EM, Beheshtian A, et al. Incidental MRI anomalies suggestive of multiple sclerosis: the radiologically isolated syndrome. Neurology 2009;72:800-05 CrossRef Medline

10. Lebrun C. The radiologically isolated syndrome. Rev Neurol (Paris) 2015;171:698-706 CrossRef Medline

11. Polman $\mathrm{CH}$, Reingold SC, Banwell B, et al. Diagnostic criteria for multiple sclerosis: 2010 revisions to the McDonald criteria. Ann Neurol 2011;69:292-302 CrossRef Medline

12. Okuda DT, Siva A, Kantarci O, et al; Radiologically Isolated Syndrome Consortium (RISC) and Club Francophone de la Sclérose en Plaques (CFSEP). Radiologically isolated syndrome: 5-year risk for an initial clinical event. PLoS One 2014;9:e90509 CrossRef Medline

13. De Stefano N, Stromillo ML, Rossi F, et al. Improving the characterization of radiologically isolated syndrome suggestive of multiple sclerosis. PLoS One 2011;6:e19452 CrossRef Medline

14. Giorgio A, Stromillo ML, Rossi F, et al. Cortical lesions in radiologically isolated syndrome. Neurology 2011;77:1896-99 CrossRef Medline
15. Sati P, Oh J, Constable RT, et al; NAIMS Cooperative. The central vein sign and its clinical evaluation for the diagnosis of multiple sclerosis: a consensus statement from the North American Imaging in Multiple Sclerosis Cooperative. Nat Rev Neurol 2016;12:714-22 CrossRef Medline

16. Suthiphosuwan $S$, Sati $P$, Guenette $M$, et al. The central vein sign in radiologically isolated syndrome. AJNR Am J Neuroradiol 2019;40:77683 CrossRef Medline

17. Oh JS, Guenette S, Absinta M, et al. The central vein sign and paramagnetic rim sign in white matter lesions of radiologically isolated syndrome (S6.003). Neurology 2019;92:(15 Suppl):S6.003

18. Rojas JI, Patrucco L, Miguez J, et al. Brain atrophy in radiologically isolated syndromes. J Neuroimaging 2015;25:68-71 CrossRef Medline

19. George IC, El Mendili MM, Inglese M, et al. Cerebellar volume loss in radiologically isolated syndrome. Mult Scler 2019 Nov 4. [Epub ahead of Print] CrossRef Medline

20. Stromillo ML, Giorgio A, Rossi F, et al. Brain metabolic changes suggestive of axonal damage in radiologically isolated syndrome. Neurology 2013;80:2090-94 CrossRef Medline

21. Giorgio A, Stromillo ML, De Leucio A, et al. Appraisal of brain connectivity in radiologically isolated syndrome by modeling imaging measures. J Neurosci 2015;35:550-58 CrossRef Medline

22. Alcaide-Leon P, Cybulsky K, Sankar S, et al. Quantitative spinal cord MRI in radiologically isolated syndrome. Neurol Neuroimmunol Neuroinflamm 2018;5:e436 CrossRef Medline

23. Thouvenot E, Hinsinger G, Demattei C, et al. Cerebrospinal fluid chitinase-3-like protein 1 level is not an independent predictive factor for the risk of clinical conversion in radiologically isolated syndrome. Mult Scler 2019;25:669-677 CrossRef Medline

24. Okuda DT, Mowry EM, Cree BA, et al. Asymptomatic spinal cord lesions predict disease progression in radiologically isolated syndrome. Neurology 2011;76:686-92 CrossRef Medline

25. Etemadifar M, Janghorbani M, Koushki MM, et al. Conversion from radiologically isolated syndrome to multiple sclerosis. Int J Prev Med 2014;5:1379-86 Medline

26. Bisulca J, De Lury A, Coyle PK, et al. MRI features associated with high likelihood of conversion of radiologically isolated syndrome to multiple sclerosis. Mult Scler Relat Disord 2019;36:101381 CrossRef Medline

27. Maia AC Jr, Rocha AJ, Barros BR, et al. Incidental demyelinating inflammatory lesions in asymptomatic patients: a Brazilian cohort with radiologically isolated syndrome and a critical review of current literature. Arq Neuropsiquiatr 2012;70:5-11 CrossRef Medline

28. Lebrun C, Bensa C, Debouverie M, et al; Club Francophone de la Sclérose en Plaques. Association between clinical conversion to multiple sclerosis in radiologically isolated syndrome and magnetic resonance imaging, cerebrospinal fluid, and visual evoked potential: follow-up of $\mathbf{7 0}$ patients. Arch Neurol 2009;66:841-46 CrossRef Medline

29. Kantarci OH, Lebrun C, Siva A, et al. Primary progressive multiple sclerosis evolving from radiologically isolated syndrome. Ann Neurol 2016;79:288-94 CrossRef Medline

30. Rossi S, Motta C, Studer V, et al. Subclinical central inflammation is risk for RIS and CIS conversion to MS. Mult Scler 2015;21:1443-52 CrossRef Medline

31. Matute-Blanch C, Villar LM, Alvarez-Cermeno JC, et al. Neurofilament light chain and oligoclonal bands are prognostic biomarkers in radiologically isolated syndrome. Brain 2018;141:1085-93 CrossRef Medline

32. Lebrun C, Le Page E, Kantarci O, et al; Club Francophone de la Sclerose en Plaques (CFSEP) and the Radiologically Isolated Syndrome Consortium (RISC) Group. Impact of pregnancy on conversion to clinically isolated syndrome in a radiologically isolated syndrome cohort. Mult Scler 2012;18:1297-1302 CrossRef Medline

33. Tintore M, Rovira A, Rio J, et al. Baseline MRI predicts future attacks and disability in clinically isolated syndromes. Neurology 2006;67:968-72 CrossRef Medline

34. Miller DH, Chard DT, Ciccarelli O. Clinically isolated syndromes. Lancet Neurol 2012;11:157-69 CrossRef Medline 
35. Brownlee WJ, Miller DH. Clinically isolated syndromes and the relationship to multiple sclerosis. J Clin Neurosci 2014;21:2065-71 CrossRef Medline

36. Giorgio A, Battaglini M, Rocca MA, et al; MAGNIMS Study Group. Location of brain lesions predicts conversion of clinically isolated syndromes to multiple sclerosis. Neurology 2013;80:234-41 CrossRef Medline

37. Sombekke MH, Wattjes MP, Balk LJ, et al. Spinal cord lesions in patients with clinically isolated syndrome: a powerful tool in diagnosis and prognosis. Neurology 2013;80:69-75 CrossRef Medline

38. Uher T, Horakova D, Bergsland N, et al. MRI correlates of disability progression in patients with CIS over 48 months. Neuroimage Clinical 2014;6:312-19 CrossRef Medline

39. Miller DH, Weinshenker BG, Filippi M, et al. Differential diagnosis of suspected multiple sclerosis: a consensus approach. Mult Scler 2008;14:1157-74 CrossRef Medline

40. Solomon AJ, Klein EP, Bourdette D. "Undiagnosing” multiple sclerosis: the challenge of misdiagnosis in MS. Neurology 2012;78:1986-91 CrossRef Medline

41. Solomon AJ, Bourdette DN, Cross AH, et al. The contemporary spectrum of multiple sclerosis misdiagnosis: a multicenter study. Neurology 2016;87:1393-99 CrossRef Medline

42. Pakpoor J, Saylor D, Izbudak I, et al. Follow-up of emergency department MRI scans suggesting new diagnosis of CNS demyelination. AJR Am J Roentgenol 2017;209:171-75 CrossRef Medline

43. Schaffler N, Kopke S, Winkler L, et al. Accuracy of diagnostic tests in multiple sclerosis: a systematic review. Acta Neurol Scand 2011;124:15164 CrossRef Medline

44. Tornatore C, Phillips JT, Khan O, et al. Consensus opinion of US neurologists on practice patterns in RIS, CIS, and RRMS: evolution of treatment practices. Neurol Clin Pract 2016;6:329-38 CrossRef Medline

45. Fernandez O, Delvecchio M, Edan G, et al. Survey of diagnostic and treatment practices for multiple sclerosis in Europe. Eur J Neurol 2017;24:516-22 CrossRef Medline

46. Carnero Contentti E, Pettinicchi JP, Caride A, et al. Decision-making on radiologically isolated syndrome among Argentinean neurologists: a survey based on clinical experience. Mult Scler Relat Disord 2019;27:61-64 CrossRef Medline

47. Boyko A. Radiologically isolated syndrome with oligoclonal bands in CSF (RIS + OCB) can be classified as high MS risk group. Mult Scler 2020;26:869-70 CrossRef Medline

48. Filippatou A, Shoemaker T, Esch M, et al. Spinal cord and infratentorial lesions in radiologically isolated syndrome are associated with decreased retinal ganglion cell/inner plexiform layer thickness. Mult Scler 2019;25:1878-87 CrossRef Medline
49. Vural A, Okar S, Kurne A, et al. Retinal degeneration is associated with brain volume reduction and prognosis in radiologically isolated syndrome. Mult Scler 2020;26:38-47 CrossRef Medline

50. Pierrot-Deseilligny C, Souberbielle JC. Vitamin D and multiple sclerosis: an update. Mult Scler Relat Disord 2017;14:35-45 CrossRef Medline

51. Traboulsee A, Simon JH, Stone L, et al. Revised Recommendations of the Consortium of MS Centers Task Force for a Standardized MRI Protocol and Clinical Guidelines for the Diagnosis and Follow-Up of Multiple Sclerosis. AJNR Am J Neuroradiol 2016;37:394-401 CrossRef Medline

52. Makhani N. Treatment considerations in the radiologically isolated syndrome. Curr Treat Options Neurol 2020;22:3 CrossRef Medline

53. Jansen PR, Dremmen $M$, van den Berg A, et al. Incidental findings on brain imaging in the general pediatric population. $N$ Engl J Med 2017;377:1593-95 CrossRef Medline

54. Makhani N. The radiologically isolated syndrome: an opportunity to prevent multiple sclerosis in children. Pediatr Neurol 2018;85:13-15 CrossRef Medline

55. Makhani N, Lebrun C, Siva A, et al; Observatoire Francophone de la Sclérose en Plaques (OFSEP), Société Francophone de la Sclérose en Plaques (SFSEP), the Radiologically Isolated Syndrome Consortium (RISC) and the Pediatric Radiologically Isolated Syndrome Consortium (PARIS). Oligoclonal bands increase the specificity of MRI criteria to predict multiple sclerosis in children with radiologically isolated syndrome. Mult Scler J Exp Transl Clin 2019;5:2055217319836664 CrossRef Medline

56. Wilbur C, Yeh EA. Radiologically isolated syndrome in children: current knowledge and future directions. Mult Scler Relat Disord 2018;24:79-84 CrossRef Medline

57. Barkhof F, Filippi M, Miller DH, et al. Comparison of MRI criteria at first presentation to predict conversion to clinically definite multiple sclerosis. Brain 1997;120:2059-69 CrossRef Medline

58. McDonald WI, Compston A, Edan G, et al. Recommended diagnostic criteria for multiple sclerosis: guidelines from the International Panel on the Diagnosis of Multiple Sclerosis. Ann Neurol 2001;50:121-27 CrossRef Medline

59. Swanton JK, Fernando K, Dalton CM, et al. Modification of MRI criteria for multiple sclerosis in patients with clinically isolated syndromes. J Neurol Neurosurg Psychiatry 2006;77:830-33 CrossRef Medline

60. Filippi M, Rocca MA, Ciccarelli O, et al. MRI criteria for the diagnosis of multiple sclerosis: MAGNIMS consensus guidelines. Lancet Neurol 2016;15:292-303 CrossRef Medline 